\title{
The Application of Computer Technology in Building Intelligentization Peng Hu
}

\author{
NanChang Institute of Science \& Technology, Nanchang,330108
}

\begin{abstract}
Keywords: Building and District Intelligentization; Automation Technology; Computer Technology; Sub-system
\end{abstract}

\begin{abstract}
Along with the development of computer technology, automation technology and network communication technology, building and district intelligentization has made a new leap and has been developed rapidly. Therefore, it is very urgent to carry out scientific management on the building and district intelligentization. Only by taking advantage of advanced project management ideas, can we guarantee its sound development and normalized the development. This paper analyzes the development of building and district intelligentization and respectively analyzes the philosophies as well as methods adopted while implementing the programs. Finally, this paper is going to specify project management methods in detail.
\end{abstract}

\section{Introduction}

Large-scale building and district intelligentization project needs the participation of a glittering array of people along with multiple techniques, large sum of capitals, materials, and equipment. Hence, management methods based on experience, intuitive impression cannot be suitable. As a result, poor management will contribute to delay of completion, poor quality and great loss. Therefore, scientific management plays a pivotal role in building and district intelligentization. Building and district intelligentization project management is very sophisticated, which covers a glittering array of subsystems and is not similar to general engineering project. It has to take the targets into consideration and the research will analyze the following: the possibilities of technique design, product, information, environment, policies etc. so as to make a comprehensive plan for the overall management. So, the project management of building and district intelligentization should have clear steps and targets.

\section{The Concept of Building and District Intelligentization}

The building and district intelligentization is actually the information automation of buildings and related groups of buildings, which is also the product of the combination of building technology and emerging information technology. In addition, the building and district intelligentization is to organically combine intelligent computer technology, communication information, information technology and the art of building to optimize information resources service and function via automatic supervisory control. In this way, can we have proper investment and make it be adapted to the requirement of society and establish safe, efficient, comfortable, convenient buildings. Building and district intelligentization is mainly made up of the following 4A:

BAS (Building Automation System)

OAS (Office Automation System)

CAS (Communication Automation System)

SAS (Security Automation System)

The subsystems of building and district intelligentization are coordinated and can be interoperable, which can be deemed as a system to realize centralized management and coordination. Thus, all subsystems can be organically integrated to construct an automatic control network for buildings. 


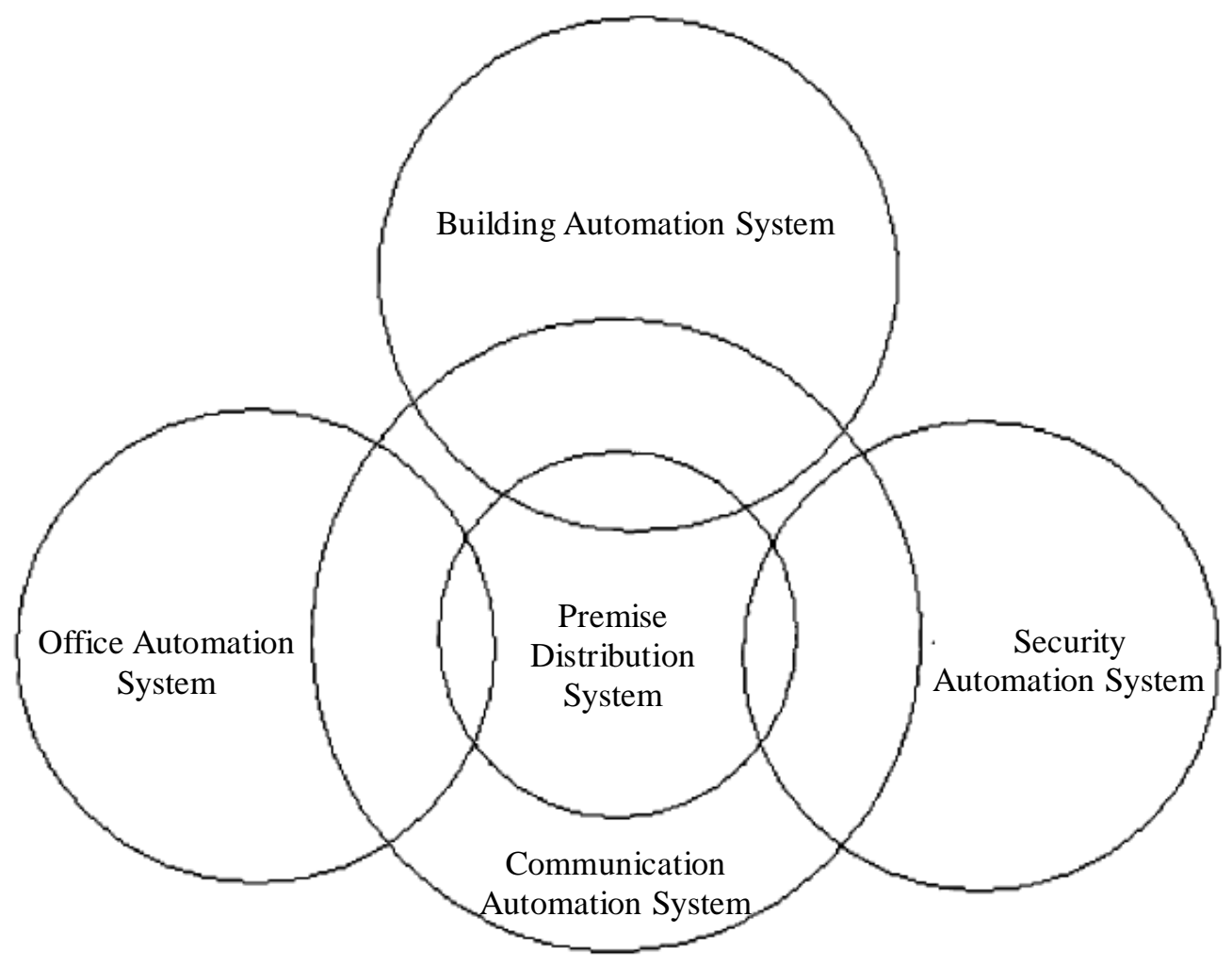

Figure 1 The relation of the subsystems building and district intelligentization

\section{Building and District Intelligentization Project Management Research System}

Building and district intelligentization project management research system is carried out based on theoretical knowledge of project management. The theoretical knowledge is concluded experience and a series of management process. At the same time, it can be divided into two dimensions based on the involved fields and function: knowledge and process. Concerning knowledge, there are 9 items, and we conclude it as core knowledge field, assisted knowledge field and overall management showing in figure 2:

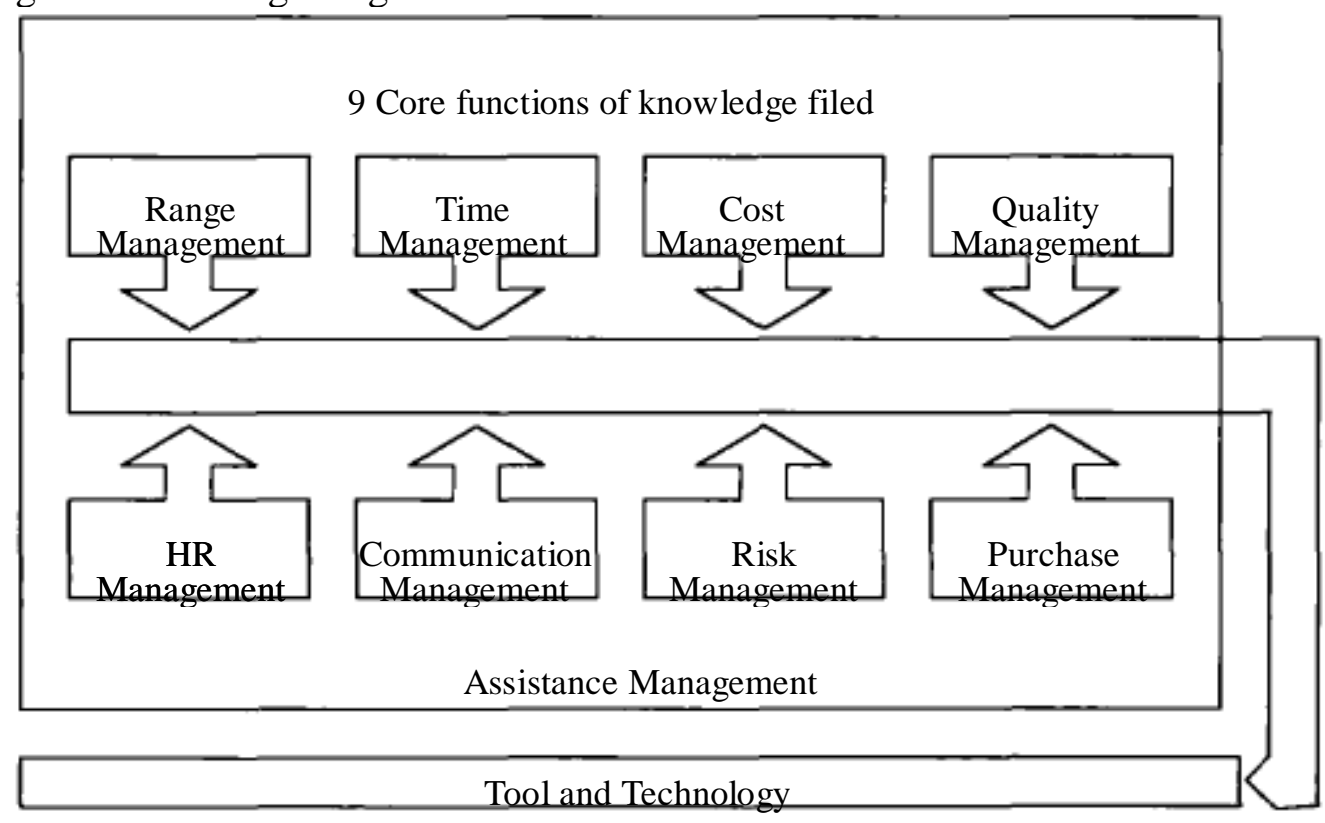

Core knowledge field includes:

Figure 2 Project knowledge field sketch map 
Project scope management: it is a process to define and control what kind of process the project is going through. The mentioned process aims to clear that project team and project stakeholders as the targets of products, we have to have mutual understanding.

Project time management: make sure all the projects can be completed in time.

Project cost management: make sure the budget is enough to finish all the process.

Project quality management: make sure all the projects can satisfy the needs.

\section{Office Automation System Construction Project Planning Strategy}

Office automation platform and transaction process platform should meet the following requirements: to begin with, it should be equipped with process dealing ability and supervision so as to multi-department cooperation and improve efficient work; secondly, provide a work platform integrating information processing and releasing so as to solve the problem of separated work process of information collecting, processing and releasing to reduce unnecessary sectors and improve convenience; thirdly, communicate with other information systems so as to avoid information inconsistency and reduce repeated work.

Therefore, in order to establish a first-rate office automation system, we have to establish an advanced, and powerful application development platform. That is to say, the adopted application development platform should be adapted to the development trend of computer technology and should be beneficial to improve management and office efficiency, contribute to the coordination among different departments and making a modern management scheme and work style. By referring to the analysis on the office automation application requirement as well as the requirement analysis of $\mathrm{OA}$, namely the information resource management platform showing in the following fig. 3:

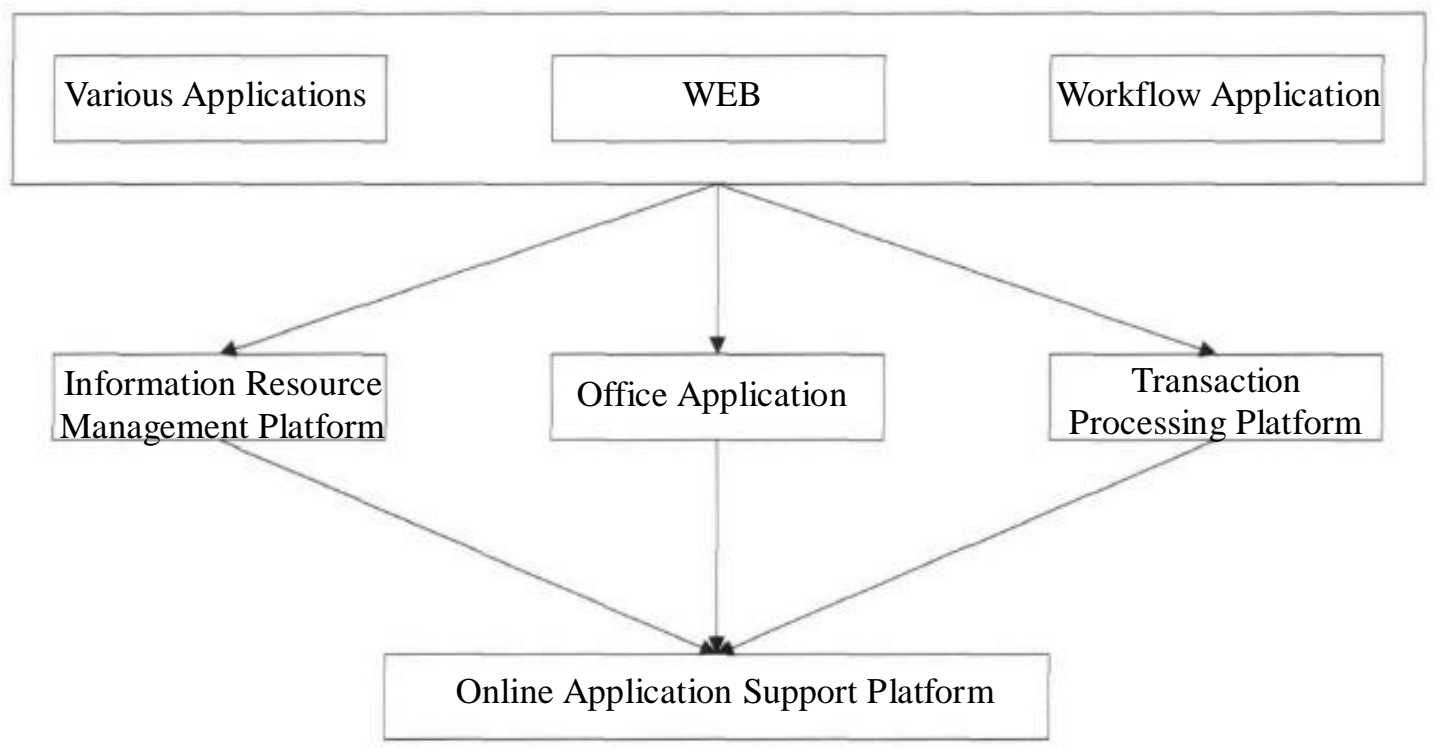

Figure 3. OA System Structure Chart

\section{Risk Management During the Implementation Period of Building and District Intelligentization}

The implementation period of building and district intelligentization must be coupled with a series of uncertainties, which cannot simply be considered as risks. We can define the risks as following: project risks refer to those negative stuff that might happen in project management as well as the potentials of unexpected results. The risk characteristics of the implementation period of building and district intelligentization show as follows:

Objectivity and universality of project risk existence: as the uncertainty of the loss, the risk does not happen based on the will of people but is objective reality. In addition, it exists everywhere and 
anytime during the implementation period. Until now, the only thing we can do is to reduce the frequency of its occurrence but completely eliminate the risk.

The contingency of the project risk and the inevitable occurrence of a large number of risks: concrete risks are caused by various adventure risks and other factors, which can be deemed as a random phenomenon. The occurrence of individual risk accidents is accidental and disorganized, but the observation and statistical analysis of a large number of risk accident data prove the existence of obvious movement rule. Thus, we can possibly use probabilistic method and other modern risk analysis methods to calculate probability of risk occurrence and the degree of loss, which actually contribute to the rapid development of risk management.

Changeability of project risk: it actually means that the quality and quantity of risks are changeable during the whole implementation process of building and district intelligentization. As the project progresses, some risks can be controlled and eliminated, and some risks will occur and be controlled, but new risks will always arise at each stage of the project.

Diversification and multi-level characteristics of project risks: Building and district intelligentization project has a long period, covers a wide range, and is equipped with various of risks. Therefore, there are multiple possible risks that might happen throughout the whole process. What's more, the complicated internal relation and external effect will also contribute to multi-level risk characteristics.

\section{Conclusion}

Building and district intelligentization project should be carried out based on a reasonable and detailed project management plan. Project management plan should define the concept of project, sub-projects, the scale of those projects and the requirement of project integration. Based on this, we have to clear the project target, as well as the target of sub-project. What's more, restrictions, construction plan, time schedule, investment scale, the feasibility of technology, economy, environment as well as invest return cycle should also be put forward. The project management plan is the basis for building and district intelligentization design, technology choosing type, and bidding, which can also be considered as the data source of project implementation and project acceptance. Moreover, it can prevent free extension because a reasonable plan will avoid the misleading of a defect mode. Furthermore, project management plan guidance will also be helpful in controlling the whole progress. We have to take project management plan as the basis and properly use capitals, which plays a pivotal role in guaranteeing the successful implementation of building and district intelligentization.

\section{Acknowledgements}

Project Fund: science and technology planning project of the Education Department in Jiangxi Province (project number: GJJ151233).

\section{References}

[1]. CiprianCostel, MUNTEANU. Arguments On Using Computer-Assisted Audit Techniques (Caat) And Business Intelligence To Improve The Work Of The Financial Auditor[J]. Management Strategies Journal, 2014, 12:83-93.

[2]. Wolfer J. Embedding Topical Elements of Parallel Programming, Computer Graphics, and Artificial Intelligence across the Undergraduate CS Required Courses[J]. International Journal of Engineering Pedagogy, 2015, 5(1).

[3]. Fatikhova L F, Saifutdiyarova E F. Computer technology in the development of emotional intelligence of children with intellectual disabilities[J]. Review of European Studies, 2015, 7(1):130-135. 
[4]. Ling Y, Ling Y. Computational Intelligence in Industrial Application: Proceedings of the 2014 Pacific-Asia Workshop on Computer Science in Industrial Application (CIIA 2014), Singapore, December 8-9, 2014[J].

[5]. El Zarka A. Developing Quantitative Assessment Metrics for Determining the Intelligence Level of a Human-Computer Interface[J]. 2014.

[6]. Lancieri L. Collective Intelligence in a Computer-Mediated Environment[J]. 2015.

[7]. Wolff J G. Application of the SP theory of intelligence to the understanding of natural vision and the development of computer vision.[J]. SpringerPlus, 2014, 3(1):1-19.

[8]. Theisens B L. The 23rd Annual Intelligent Ground Vehicle Competition: Building Engineering Students into Robotists[J]. Electronic Imaging, 2016.

[9]. Flanigan A E, Peteranetz M S, Shell D A, et al. Implicit Intelligence Beliefs of Computer Science Students: Exploring Change Across the Semester[J]. Contemporary Educational Psychology, 2016, 48:179-196.

[10]. Ozkul T. Assessment of intelligence of user-computer interface[C]// International Conference on Information and Communication Systems. IEEE, 2016. 